\title{
Prediction of severe exacerbations and mortality in COPD: the role of exacerbation history and inspiratory capacity/total lung capacity ratio
}

This article was published in the following Dove Press journal: International Journal of COPD

\author{
João Cardoso ${ }^{1,2}$ \\ Ricardo Coelho' \\ Carla Rocha' \\ Constança Coelho ${ }^{3}$ \\ Luísa Semedo ${ }^{1,2}$ \\ A Bugalho Almeida ${ }^{3}$ \\ 'Department of Respiratory Medicine, \\ Hospital de Santa Marta, Centro \\ Hospitalar Lisboa Central, Lisboa, \\ Portugal; ${ }^{2}$ Nova Medical School/ \\ Faculdade de Ciências Médicas, \\ Universidade Nova de Lisboa, \\ Portugal; ${ }^{3}$ Faculdade de Medicina, \\ Universidade de Lisboa, Portugal
}

Correspondence: João Cardoso Department of Respiratory Medicine, Hospital de Santa Marta, Centro Hospitalar Lisboa Central, Rua de Santa Marta, I I69-1024 Lisboa, Portugal Tel/fax +35 I2/3594268

Email joaocardoso@meo.pt
Background: Severe exacerbations and mortality are major outcomes in COPD, and risk factors for these events are actively searched for. Several predictors of mortality have been identified in COPD. The inspiratory capacity/total lung capacity (IC/TLC) ratio has been shown to be a strong predictor of all cause and respiratory mortality in patients with COPD. The major objectives of this study were to analyze which clinical parameters, including lung volumes, were the best predictors of the 5-year cumulative risk of hospital admissions or death and the 5-year risk of exacerbations, in stable COPD patients.

Methods: This study retrospectively reviewed data from 98 stable COPD patients, consecutively recruited in 2012. Forced expiratory volume in $1 \mathrm{~s}\left(\mathrm{FEV}_{1}\right)$, modified Medical Research Council dyspnea scale, exacerbation history (ExH), Global Initiative for Chronic Obstructive Lung Disease (GOLD) 2011 groups, and lung volumes were reviewed. Five years later, this population was evaluated for cumulative exacerbations, hospital admissions, and mortality. All the population, and GOLD group D separately, were analyzed.

Results: The cumulative 5-year combined risk of hospital admission or death was significantly predicted by the ExH and the IC/TLC ratio. Analyzing separately group D, FEV was the only predictor of this outcome. The frequency of exacerbations in the previous year was the best predictor of future cumulative 5-year risk of subsequent exacerbations, both for the total population and the GOLD D group.

Conclusion: ExH and IC/TLC ratio were the best predictors of the most severe outcomes in

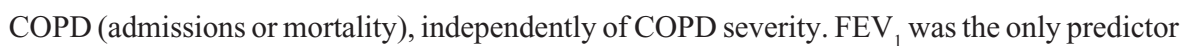
of the cumulative 5-year combined risk of hospital admission or death in the GOLD D group. ExH was the best predictor of 5-year cumulative future risk of exacerbations. Besides FEV ${ }_{1}$ and ExH, the IC/TLC ratio can be a useful predictor of severe outcomes in COPD.

Keywords: $\mathrm{FEV}_{1}$, severe outcomes, admissions, mortality, IC/TLC ratio

\section{Introduction}

The prognosis of COPD is a major concern in the present management of the disease, as it is a significant cause of mortality ${ }^{1}$ and estimated to be increasing. ${ }^{2-5}$ COPD is the 4th leading cause of death worldwide, and it is estimated that, by 2020 , it will be the 3 rd leading cause. ${ }^{6}$

Identifying high risk patients and the factors that can best predict the worse outcomes, severe exacerbations with hospital admissions and risk of death, are major objectives that should be applied in clinical practice. ${ }^{5}$

COPD is a complex and heterogeneous disease, and several factors are related to adverse events. Exacerbations are major risk factors for progression of disease, ${ }^{7}$ 
significant worsening of symptoms,${ }^{8}$ exercise capacity, ${ }^{8}$ poor quality-of-life, ${ }^{9}$ and mortality. ${ }^{10}$ Severe exacerbations resulting in hospital admissions have significant in-hospital mortality. ${ }^{11,12}$ Survival after admission is poor and related to the number of previous severe exacerbations..$^{11,13,14}$

The prognosis of COPD is highly related to the severity and frequency of acute exacerbations, especially with the severe ones that result in hospital admission. ${ }^{11,15}$ Both severe exacerbations and mortality are major outcomes in COPD, and risk factors for these events are actively searched for in order to modify the course of the disease. ${ }^{16}$

Several predictors of mortality in COPD have been identified: forced expiratory volume in $1 \mathrm{~s}\left(\mathrm{FEV}_{1}\right)$, age, body mass index (BMI), dyspnea, exercise capacity, exacerbation frequency, previous severe exacerbations, BODE index, and the Global Initiative for Chronic Obstructive Lung Disease (GOLD) classes. ${ }^{17-23}$

The mortality predictive capacity of the GOLD 2011 classification has been compared to the previous stratification using $\mathrm{FEV}_{1}$ severity, and it has been demonstrated that the multicomponent definition is not a better predictor than FEV $_{1}$ alone. ${ }^{21}$

Lung function studies in COPD are mainly derived from spirometry, and $\mathrm{FEV}_{1}$ is a powerful marker of the severity, progression of the disease, and risk of mortality. ${ }^{18,21,24}$ However, $\mathrm{FEV}_{1}$ is poorly correlated with clinical variables such as symptoms or exacerbations.

Other lung function variables (such as lung volumes, diffusing capacity for carbon monoxide [DLCO], exercise capacity, blood gases, or presence of respiratory insufficiency) are known to represent useful parameters that can help to understand the physiopathology of dyspnea, exercise limitation, and hypoxemia. These tests are recommended in certain circumstances, but are not usually used as predictors for adverse events in conjunction with other clinical dimensions. ${ }^{16}$

It is known that the inspiratory capacity/total lung capacity (IC/TLC) ratio, that represents the static hyperinflation, sometimes designated as the inspiratory fraction, is highly related to dyspnea and exercise capacity, as it is worsened in exercise (dynamic hyperinflation). ${ }^{25,26}$ Several studies have concluded that this ratio can be very useful in understanding clinical effects (dyspnea, ${ }^{27}$ exercise capacity limitation, ${ }^{28}$ muscular weakness, ${ }^{29}$ and eventually exacerbations ${ }^{30,31}$ ) and can be used as a strong predictor of all cause and respiratory mortality in COPD patients. ${ }^{25,32,33}$ However, these findings have not been applied in recommendations and clinical practice.
The major objectives of this study were to analyze which clinical parameters, including lung volumes determination, and the IC/TLC ratio in particular, were the best predictors of the 5-year cumulative risk of hospital admissions or death and the 5-year risk of exacerbations, in stable COPD patients.

\section{Methods \\ Design and population}

We used in this study a previous sample of 100 patients with COPD followed at the ambulatory Pulmonary Clinic of Hospital de Santa Marta, Lisbon, Portugal. Stable COPD patients were consecutively recruited between January and February 2012, in order to compare their different classification by the GOLD 2011 versus the previous GOLD 2007. Patients had a clinical diagnosis of COPD confirmed by a post bronchodilator forced expiratory volume in $1 \mathrm{~s} /$ forced vital capacity $\left(\mathrm{FEV}_{1} / \mathrm{FVC}\right)<0.70$. Patients were in a stable state, and with no exacerbations in the previous 3 months. At that time, patients with a history of asthma, other associated lung conditions, previous lung surgery, lung cancer, or significant and unstable cardiac condition were excluded. This sample was classified according to the ABCD of GOLD $2011\left(\mathrm{FEV}_{1}\right.$, modified Medical Research Council [mMRC] dyspnea scale, previous year exacerbations), and all patients performed spirometry and lung volume determination by plethysmography by the same respiratory technicians. Not all patients had a DLCO or blood gases determination, so we excluded these parameters of the analysis. All lung function variables analyzed are postbronchodilator. Respiratory function tests were performed according to ATS/ERS (American Thoracic Society/European Respiratory Society) recommendations, ${ }^{34,35}$ and the European Community for Steel and Coal/ERS reference values were used. ${ }^{36}$

The study involved a 5-year retrospective review of patients who presented to the Pulmonary Clinic of the Hospital. Of this sample of 100 patients, 98 patients were included in this study, as two patients had no lung volume determination. Patients were considered alive if they had a regular follow-up in the first 4 months of 2017. Death of patients was confirmed by consulting our records or the national registry. The allcause mortality is used in this study, as the cause of death was not possible to identify in all patients.

\section{Data collection and follow-up}

Data were collected by the authors from the clinical files, and admission and discharge records. Data collected included baseline demographic data, respiratory function assessments, and previous exacerbations. Patients were categorized according to the GOLD 2011 classification as GOLD A, B, C, 
or $\mathrm{D}\left(\mathrm{GOLD} \mathrm{A}-\mathrm{FEV}_{1} \geq 50 \%, \mathrm{mMRC}<2\right.$, Exacerbations $<2$; GOLD B $-\mathrm{FEV}_{1} \geq 50 \%, \mathrm{mMRC} \geq 2$, Exacerbations $<2$; GOLD C $-\mathrm{FEV}_{1}<50 \%$, mMRC $<2$, Exacerbations $\geq 2$; GOLD D $-\mathrm{FEV}_{1}<50 \%, \mathrm{mMRC} \geq 2$, Exacerbations $\left.\geq 2\right) .{ }^{37}$

Follow-up extended until 60 months (5 years) after the initial baseline data collection. Hospitalizations, exacerbations, and deaths were collected from the clinical files, and admission and discharge records. We analyzed the total population and the GOLD D group separately.

\section{Outcomes}

The primary composite outcome was death or admissions from the baseline data collection until 60 months. The secondary outcome was exacerbations from the baseline data collection until 60 months.

\section{Statistical analysis}

All categorical variables were expressed as numbers or percentages. All continuous variables were expressed using median and minimum-maximum. Between group analysis was performed using the Mann-Whitney $U$-test or the $\chi^{2}$ test, respectively, for continuous and discrete variables. Exploratory univariate analyses were performed, followed by multivariate regression analyses. Variables selected for the multivariate analyses were those with an $\alpha<0.05$ (two-sided) on univariate analyses. Variables were selected using the backward step elimination. The Bonferroni correction was applied to both univariate and multivariate analyses when necessary. Tests were considered significant at $\alpha=0.05$ significance level (two-sided). SPSS v20 was used for statistical analysis.

\section{Ethics committee approval}

This study was approved by the Institutional Review Board of Hospital de Santa Marta, CHLC. The need for written informed consent from all participants was waived because this was a retrospective study with anonymized patient data.

\section{Results}

\section{Baseline values by GOLD group}

There were several significant differences on baseline parameters between the GOLD groups (Table 1 and Figures 1-4).

Forty-nine percent of patients were classified as group D, and $70 \%$ as groups B and D. Groups C and D had higher than normal static lung volumes, consistent with the presence of hyperinflation and emphysema (total lung capacity, intrathoracic gas volume, residual volume). Interestingly, group D had a significantly lower IC than group C (Table 1). $\mathrm{FEV}_{1}$ declined across groups, being worse in group $\mathrm{D}$. There was no difference between groups A and B (Figure 1). The $\mathrm{mMRC}$ was significantly higher in group $\mathrm{D}$ compared to group B (Figure 2). All lung function parameters showed differences between GOLD groups. Previous year exacerbations were lower than two in group $\mathrm{C}$, which means that these patients were mainly classified by their lung function severity. Group D had more than two exacerbations, on average (Figure 3). IC/TLC (\%) also declined across groups, being worse in group D. There was no difference between groups A and B (Figure 4).

\section{Comparison of variables at baseline and outcomes at 5 years by GOLD group}

Table 2 shows the comparison of variables at baseline and outcomes at 5 years by GOLD group. Almost $70 \%$ of GOLD C patients and almost $90 \%$ of GOLD D patients experienced exacerbations during the 5-year follow-up. There were 24 deaths during follow-up, $67 \%$ of which were in group D, meaning that the death rate in the other three groups was $33 \%$. There were 53 admissions during follow-up, 67.3\%

Table I Baseline characteristics by GOLD 20 I I group

\begin{tabular}{|c|c|c|c|c|}
\hline Parameter & $A(n=16)$ & $B(n=2 I)$ & $C(n=13)$ & $D(n=48)$ \\
\hline Age (years) & $63.0(49.0-80.0)$ & $65.0(49.0-80.0)$ & $70.0(49.0-74.0)$ & $67.0(44.0-80.0)$ \\
\hline Female, n (\%) & $I(6.2)$ & $7(33.3)$ & I (7.7) & $6(12.5)$ \\
\hline IC (\%) & $110.5(76.0-143.0)^{\mathrm{a}, \mathrm{c}}$ & $106.0(47.0-161.0)^{\mathrm{b}}$ & $96.0(51.0-115.0)^{c}$ & $72.0(3|.0-| 4 \mid .0)$ \\
\hline $\mathrm{FEV}_{1} / \mathrm{FVC}$ & $65.9(36.0-79.9)^{\mathrm{a}}$ & $56.5(38 . I-79.6)^{b}$ & $38.5(27.5-69.9)$ & $35.1(23.1-63.9)$ \\
\hline TLC (\%) & $110.0(75.0-135.0)$ & $108.0(63.0-157.0)^{c}$ & $\mid 26.0(95.0-14 \mid .0)^{c}$ & $123.0(6 \mid .0-184.0)$ \\
\hline ITGV (\%) & $109.5(74.0-167.0)^{\mathrm{a}}$ & II $4.0(78.0-187.0)^{b}$ & $173.0(100.0-189.0)$ & I 64.0 (73.0-294.0) \\
\hline RV (\%) & II $0.5(42.0-158.0)^{\mathrm{a}}$ & $121.0(70.0-191.0)^{\mathrm{b}}$ & $183.0(|2| .0-216.0)$ & $197.5(65.0-437.0)$ \\
\hline
\end{tabular}

Notes: All measures taken postbronchodilation. All values, except gender, presented as median (minimum-maximum). The predicted values used for lung function are the ECSC/ERS equations. ${ }^{36}$ GOLD 201 I groups defined in the "Data collection and follow-up" section. ${ }^{a} P<0.00$ I A vs C/D; $b P<0.00$ I B vs C/D; ${ }^{c} P=0.005$.

Abbreviations: ECSC, European Community for Steel and Coal; GOLD, Global Initiative for Chronic Obstructive Lung Disease; IC, inspiratory capacity; FEV ${ }_{1}$, forced expiratory volume in I s; FVC, forced vital capacity; TLC, total lung capacity; ITGV, intrathoracic gas volume; RV, residual volume. 


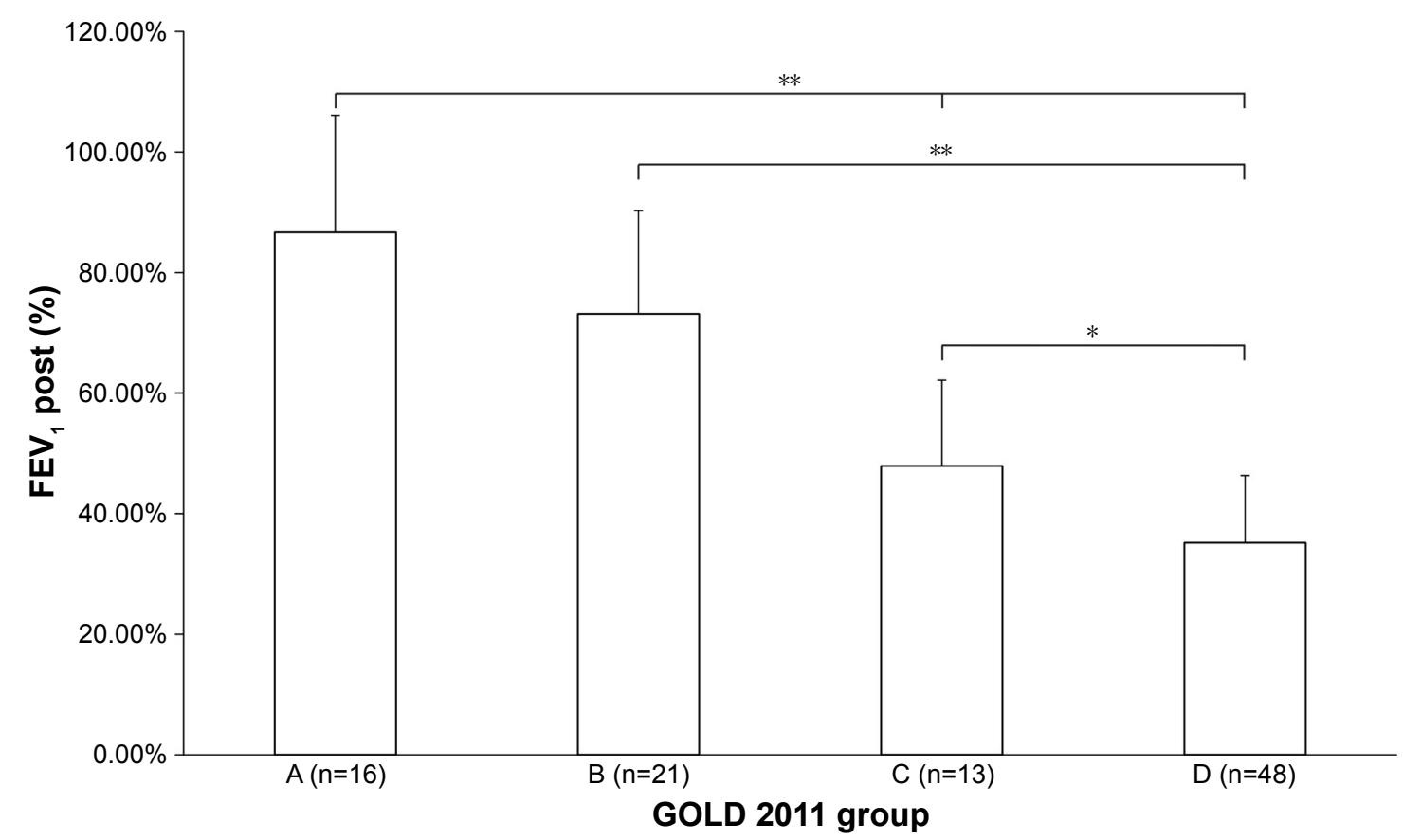

Figure I Baseline FEV, between GOLD groups.

Notes: $* P<0.01$; $* * P<0.001$. GOLD 201 I groups defined in the "Data collection and follow-up" section.

Abbreviations: $\mathrm{FEV}_{1}$, forced expiratory volume in I s; GOLD, Global Initiative for Chronic Obstructive Lung Disease.

of which were in group $\mathrm{D}$, which was statistically different from the other three groups combined $(32.7 \%, P<0.001)$. Exacerbations in the previous year, IC/TLC post $<25 \%$, death or admission after 5 years, and exacerbations after 5 years were all different when comparing GOLD A and GOLD D patients. We analyzed the IC/TLC ratio in two groups, those with a ratio lower than $25 \%$ versus those higher than $25 \%$, as has been done in previous studies of the role of IC/TLC ratio.

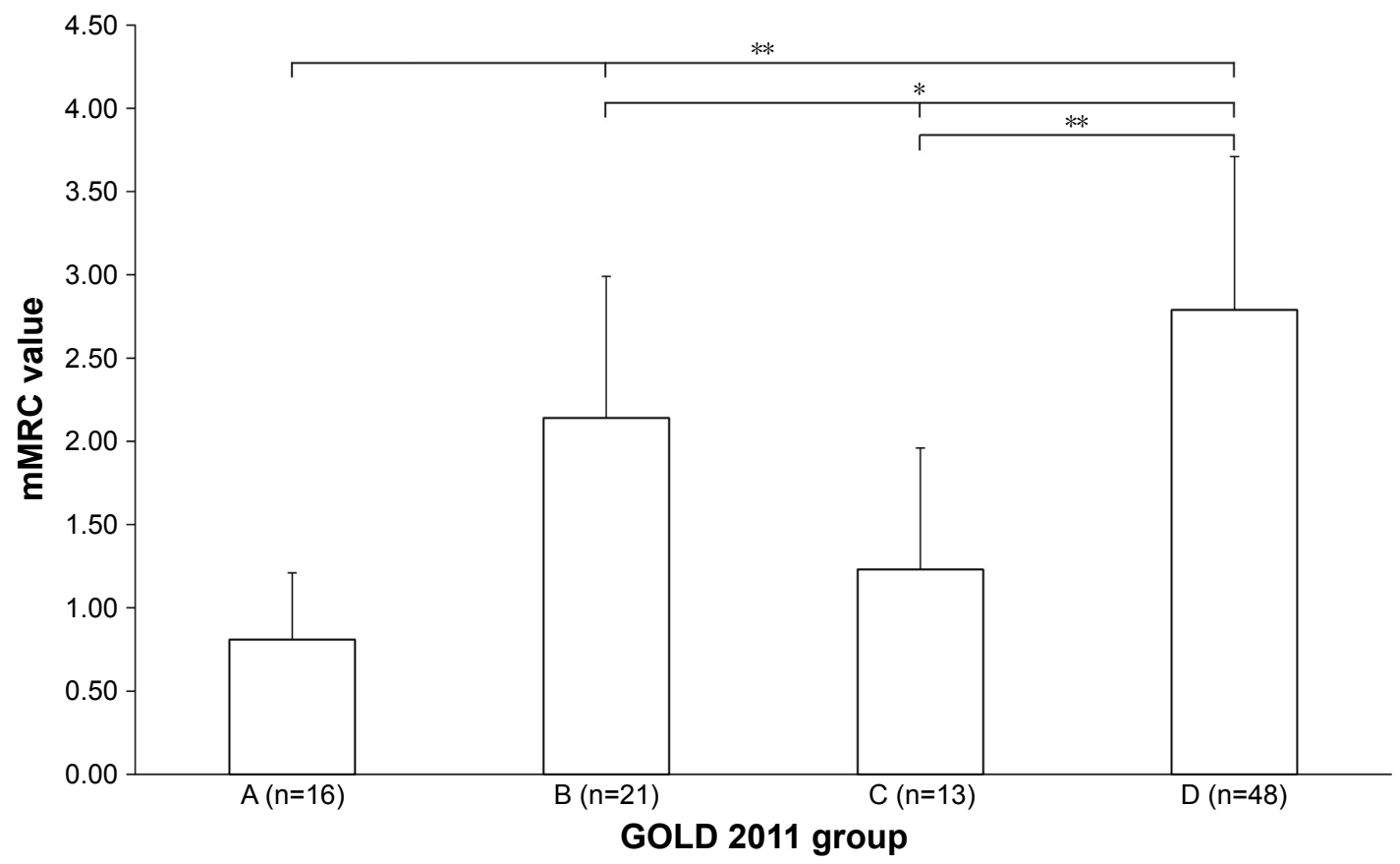

Figure 2 Baseline mMRC between GOLD groups.

Notes: ${ }^{*}<<0.01 ;{ }^{* *} P<0.001$. GOLD 201 I groups defined in the "Data collection and follow-up" section.

Abbreviations: mMRC, modified Medical Research Council; GOLD, Global Initiative for Chronic Obstructive Lung Disease. 


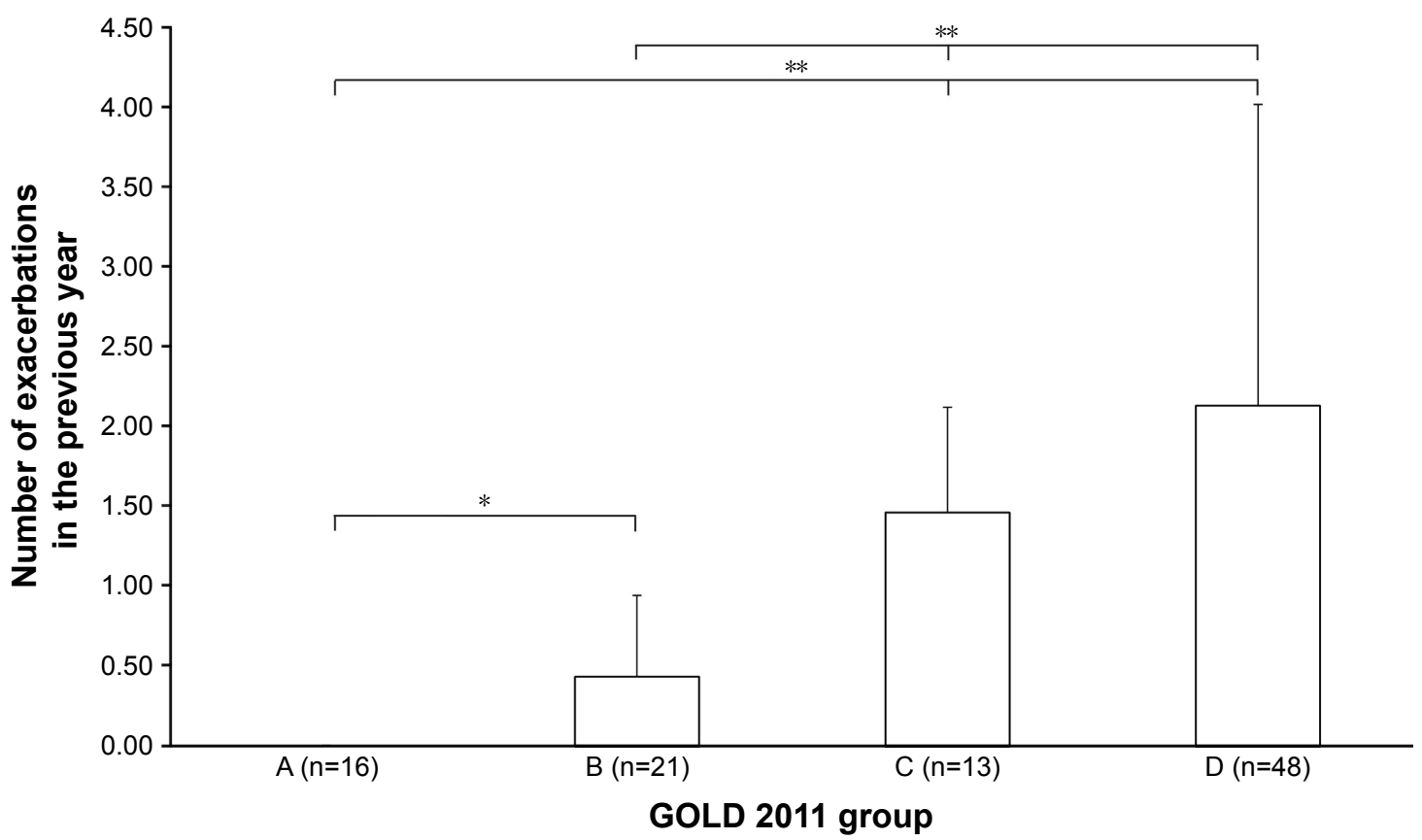

Figure 3 Exacerbations in the previous year between GOLD groups.

Notes: $* P<0.01 ; * * P<0.001$. GOLD 201 I groups defined in the "Data collection and follow-up" section.

Abbreviation: GOLD, Global Initiative for Chronic Obstructive Lung Disease.

This ratio was above $25 \%$ in almost all group $\mathrm{A}$ and $\mathrm{B}$ patients, and lower than $25 \%$ in $46 \%$ and $40 \%$ of groups $C$ and $\mathrm{D}$, respectively, with no statistical difference between these latter two groups.

\section{Primary outcome (death or admission)}

The cumulative 5-year combined risk of hospital admission or death was significantly predicted by the exacerbation history $(\mathrm{ExH})$ and the IC/TLC ratio for the total population

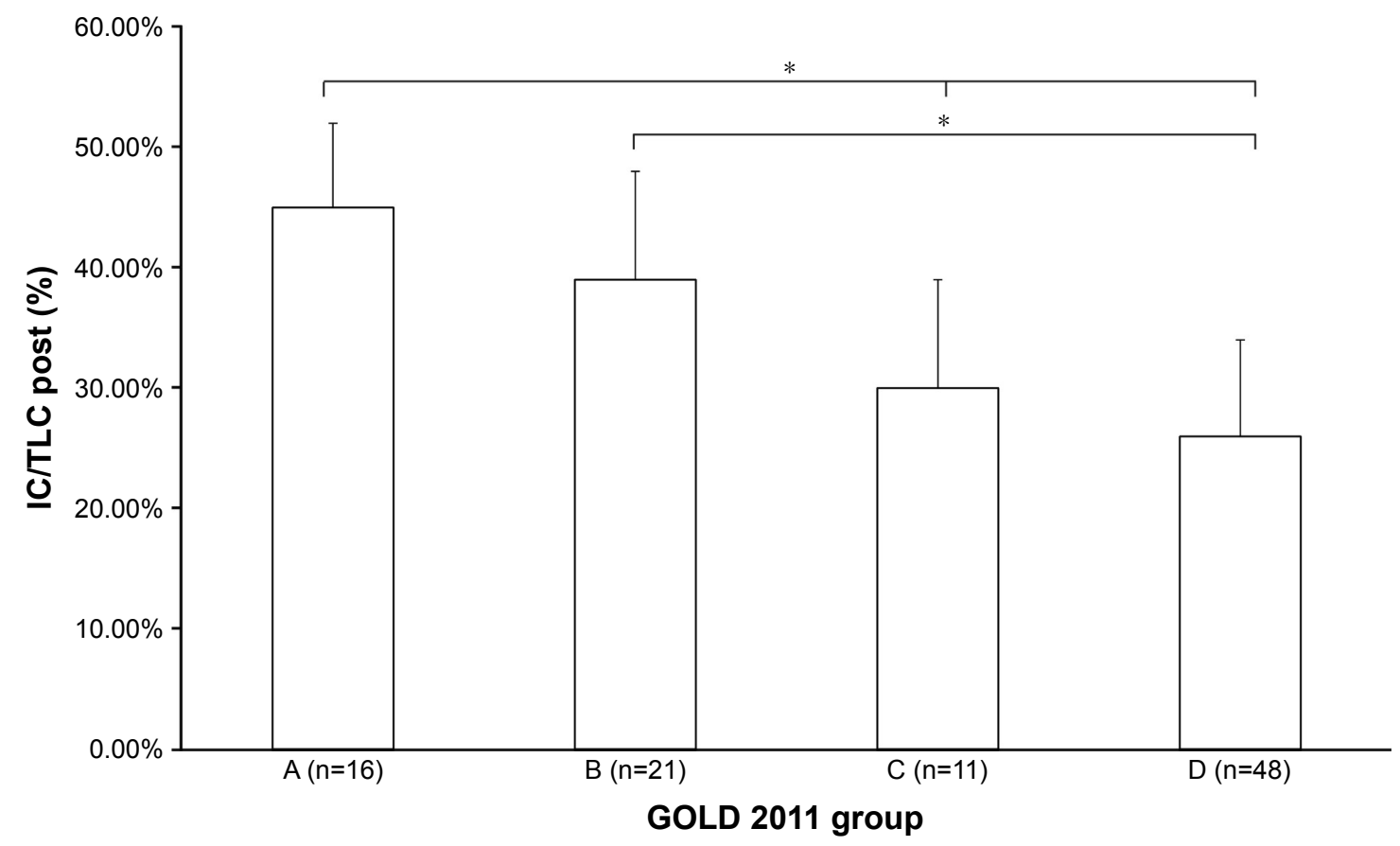

Figure 4 Baseline IC/TLC between GOLD groups.

Notes: $* P<0.00$ I. GOLD 201 I groups defined in the "Data collection and follow-up" section.

Abbreviations: IC/TLC, inspiratory capacity/total lung capacity; GOLD, Global Initiative for Chronic Obstructive Lung Disease. 
Table 2 Comparison of variables at baseline and outcomes at 5 years by GOLD 201 I group

\begin{tabular}{lllll}
\hline Parameter & $\mathbf{A}(\mathbf{n}=\mathbf{I 6})$ & $\mathbf{B}(\mathbf{n}=\mathbf{2} \mathbf{I})$ & $\mathbf{C ~ ( n = 1 3 )}$ & $\mathbf{D}(\mathbf{n}=\mathbf{4 8})$ \\
\hline Ex previous year & $0(0.0)^{\mathrm{a}, \mathrm{b}}$ & $9(42.9)^{\mathrm{c}, \mathrm{d}}$ & $\mathrm{I} 2(92.3)$ & $42(87.5)^{\mathrm{c}, \mathrm{d}}$ \\
IC/TLC $<25 \%$ & $0(0.0)^{\mathrm{e}}$ & $\mathrm{I}(4.8)^{\mathrm{d}}$ & $6(46.2)$ & $19(39.6)^{\mathrm{d}, \mathrm{e}}$ \\
D or A after 5 years & $3(18.8)^{\mathrm{a}}$ & $6(28.6)^{\mathrm{d}}$ & $8(61.5)$ & $35(72.9)^{\mathrm{d}}$ \\
Ex after 5 years $^{\mathrm{d}}$ & $9(56.2)^{\mathrm{b}}$ & $5(23.8)^{\mathrm{c}}$ & $9(69.2)$ & $43(89.6)^{\mathrm{c}}$ \\
\hline
\end{tabular}

Notes: IC/TLC measures taken post-bronchodilation. All values presented as $\mathrm{n}$ (\%). GOLD $201 \mathrm{I}$ groups defined in the "Data collection and follow-up" section. ${ }^{a} P<0.001$ A vs $C / D$; ${ }^{b} P<0.01$ A vs $B / D$; ${ }^{c} P<0.001$; ${ }^{d} P<0.01$; ${ }^{e} P<0.01$.

Abbreviations: GOLD, Global Initiative for Chronic Obstructive Lung Disease; Ex, exacerbations; IC/TLC, inspiratory capacity/total lung capacity; D or A, death or admission.

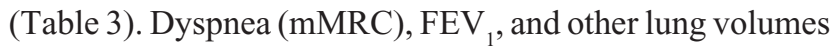
did not predict this outcome. Analyzing group D separately, of the most severe and high risk patients, $\mathrm{FEV}_{1}$ was the only predictor of this outcome.

\section{Secondary outcome}

The frequency of exacerbations in the previous year was the best predictor of future cumulative 5-year risk of subsequent exacerbations, both for the total population and for the GOLD D group (Table 3). No other parameter had significance concerning this outcome.

\section{Discussion}

We found in our study that ExH and IC/TLC ratio were the best predictors of the most severe outcomes in COPD (admissions or mortality), and they can be applied to all COPD patients independently of their severity. $\mathrm{FEV}_{1}$ was the only predictor of the cumulative 5-year combined risk of hospital admission or death in GOLD D COPD patients. ExH was the best predictor of 5-year cumulative future risk of exacerbations in the whole population sample. To our knowledge, this is the first study to analyze the 5-year prediction of the combination of exacerbations, hospital admissions, and mortality in stable COPD patients.
Major factors for a poor outcome in COPD are severe exacerbations and risk of mortality. Current knowledge considers that $\mathrm{FEV}_{1}$, dyspnea severity, exacerbations frequency and severity, and GOLD classes are good predictors of progression of COPD and risk of mortality. ${ }^{5}$ These variables can be easily obtained in a clinical setting when predicting future risk and can be important in order to offer the best treatment available to reduce risk of severe exacerbations with hospital admissions and mortality. Complementary parameters have been investigated to better predict these risks in the most severe patients and at high risk of worse outcomes. The previous year exacerbation frequency and severity is considered to be the best predictor of future risk of exacerbations, ${ }^{20}$ but this does not have the discriminative capacity to identify which patients will be at risk of a severe exacerbation and hospital admission and risk of mortality.

These were the major objectives of our study: identifying which parameters easily obtained in clinical practice can be predictors of the combined risk of hospital admissions or death and exacerbations. With this study, we tried to simulate the usual clinical context in the management of COPD patients. Most importantly, we tried to identify risk factors that can be used in stable COPD patients, followed in an ambulatory setting that can predict future major events besides the accepted important role of $\mathrm{FEV}_{1}$, dyspnea severity, and previous exacerbations.

The future risk of exacerbations has been considered to be best predicted by the frequency and severity of exacerbations in the previous year. ${ }^{20}$ Besides $\mathrm{FEV}_{1}$, the role of other lung function tests is less clear, the exception being the IC/TLC ratio. ${ }^{25,32,33}$ This ratio is very well correlated with dyspnea, as it represents static hyperinflation that worsens on exercise (dynamic hyperinflation resulting in exercise limitation caused by exercise dyspnea), such as in emphysema. ${ }^{26}$ This ratio can also be associated with more frequent exacerbations, ${ }^{31}$ risk of severe ones, and risk of death. ${ }^{25,32,33}$

Table 3 Predictors of death or readmission after 5 years and of exacerbations after 5 years on multivariate analyses

\begin{tabular}{|c|c|c|c|c|c|c|c|c|}
\hline \multirow[t]{2}{*}{ Subgroup/predictor(s) } & \multicolumn{4}{|c|}{ Death or readmission after 5 years } & \multicolumn{4}{|c|}{ Exacerbations after 5 years } \\
\hline & $\overline{\mathbf{B}}$ & $\operatorname{Exp}(B)$ & $95 \% \mathrm{Cl}$ for $\operatorname{Exp}(\mathrm{B})$ & $P$-value & $\overline{\mathbf{B}}$ & $\operatorname{Exp}(B)$ & $95 \% \mathrm{Cl}$ for $\operatorname{Exp}(\mathrm{B})$ & $P$-value \\
\hline \multicolumn{9}{|l|}{ GOLD D 20II Group } \\
\hline Age (years) & 0.122 & 1.130 & $0.998-1.279$ & 0.054 & 0.125 & 1.133 & $0.858-1.495$ & 0.379 \\
\hline $\mathrm{FEV}_{1}(\%)$ & -0.215 & 0.807 & $0.680-0.957$ & 0.014 & 0.042 & 1.043 & $0.764-1.422$ & 0.793 \\
\hline Exacerbations in previous year $(\mathrm{n})$ & 1.860 & 6.423 & $0.978-42.179$ & 0.053 & 4.232 & 68.855 & 17.364-273.039 & $<0.001$ \\
\hline \multicolumn{9}{|l|}{ Total population } \\
\hline Age (years) & 0.052 & 1.053 & $0.992-1.118$ & 0.090 & 0.003 & 1.003 & $0.863-1.165$ & 0.973 \\
\hline IC/TLC (\%) & -10.465 & 0.000 & $0.000-0.023$ & 0.002 & 11.203 & $7.3 \times 10^{4}$ & $2.4 \times 10^{-5}-2.3 \times 10^{14}$ & 0.315 \\
\hline Exacerbations in previous year $(\mathrm{n})$ & 0.817 & 2.263 & I.189-4.306 & 0.013 & 4.010 & 55.120 & $19.216-158.103$ & $<0.001$ \\
\hline
\end{tabular}

Note: GOLD D 201 I group defined in the "Data collection and follow-up" section.

Abbreviations: GOLD, Global Initiative for Chronic Obstructive Lung Disease; FEV , forced expiratory volume in I s; IC/TLC, inspiratory capacity/total lung capacity; $\mathrm{B}$, unstandardized coefficient; $95 \% \mathrm{Cl}, 95 \%$ confidence interval for $\operatorname{Exp}(\mathrm{B})$. 
Other studies have proved the importance of this ratio and of the static hyperinflation. The NETT Trial has demonstrated that surgical lung volume reduction reduces the frequency of COPD exacerbations and mortality in selected cases of emphysema, ${ }^{22}$ and the study by French et al $^{32}$ also concluded that the IC/TLC ratio is a good predictor of mortality in emphysema. However, these studies did not compare the value of different important baseline clinical parameters, such as $\mathrm{FEV}_{1}$, dyspnea, and ExH, or the GOLD group, with lung volumes, neither did they evaluate which of these parameters would be more predictive of 5-year cumulative exacerbations or the combined 5-year risk of admission (severe exacerbation) or death.

\section{Findings in univariate analysis}

All lung function parameters showed differences between GOLD A and GOLD D patients. Baseline IC/TLC did not differ between GOLD A and GOLD B patients, although exacerbations after 5 years were higher in the GOLD A group compared to the GOLD B group $(56.2 \%$ vs $23.8 \%, P<0.01)$. The latter result was unexpected and may be related to noncompliance or undertreatment of GOLD A patients.

\section{Findings in multivariate analysis}

Our finding that exacerbations in the previous year are the strongest predictor of future exacerbations is in line with previous findings ${ }^{20}$ and the GOLD guidelines. ${ }^{5}$

The cumulative 5-year combined risk of hospital admission or death was significantly predicted by the ExH and the IC/TLC ratio for the total population. In our opinion, ExH and the IC/TLC ratio should be used more often in clinical practice, even in the less severe patients, reinforcing the extreme value of previous exacerbations, independent of their phenotype (which was not analyzed in our study). Our findings identify IC/TLC as another possible respiratory function parameter of the worse outcomes in COPD.

We think that determination of IC/TLC by plethysmography, even if not available in all heath care settings as spirometry, can be a useful parameter to identify patients with worse outcomes. Baseline determination of IC/TLC, conjugated with $\mathrm{FEV}_{1}, \mathrm{mMRC}$, and $\mathrm{ExH}$, can be a powerful tool to identify high risk patients. In patients with progressive disease, clinical and functional worsening, repeated IC/ TLC determination would be helpful in evaluating treatment response.

If only the GOLD D group (half of patients in the sample) was analyzed, $\mathrm{FEV}_{1}$ was the only predictor of cumulative 5-year combined risk of hospital admission or death. The suggestion that these patients can be extremely important in the management of COPD is somehow implicit in the recent GOLD 2017 revision (even though $\mathrm{FEV}_{1}$ is no longer included in the classification), ${ }^{5}$ in a recent proposal of the CERO index by Celli et $\mathrm{al}^{38}$ (a composite index of major outcomes using admissions and mortality, to use in clinical studies, as was our case), and also in the recent Spanish GesEPOC guidelines, 2017 revi$\operatorname{sion}^{39}$ that considers that these patients, GOLD D, are high risk patients. It is our opinion that the lack of prediction of exacerbations and IC/TLC in the separate multivariate analysis of the GOLD D group may be related to the small number of patients.

\section{Strengths and limitations}

Some of the strengths of this study are the fact that all patients were treated according to the GOLD 2011 guidelines, ${ }^{37}$ by the same physicians, lung function testing were obtained by the same technicians, and all patients were included in a stable state (no exacerbations in the previous 3 months). Even in the context of a small sample, some variables, such as previous exacerbation frequency and IC/TLC ratio, were significantly associated with the defined outcomes in univariate and multivariate statistical analysis. This finding is very important, as it can be extremely useful to apply in clinical practice, given the small number of patients necessary to have a significant predictor capacity of the major outcomes. Moreover, these parameters are applicable to all GOLD groups of COPD patients, and, therefore, can be valid in a general clinical context, and not in a specific or special population (emphysematous phenotype or previous severe exacerbations only). ${ }^{22,32}$

The major limitations of this study include its retrospective design, the fact that the population studied was followed in a secondary respiratory outpatient clinic, the small sample size (although homogeneous during the time frame of inclusion), being a single center study, and the non-inclusion in the analyses of DLCO, blood gases, and exercise capacity, due to the fact that they have not been performed in all patients.

\section{Conclusion}

We found that ExH and IC/TLC ratio were the best predictors of the most severe outcomes in COPD (admissions or mortality), and that they can be applied to all COPD patients independently of their severity. In this study, $\mathrm{FEV}_{1}$ was the only predictor of the cumulative 5-year combined risk of hospital admission or death in high risk COPD patients: $\mathrm{FEV}_{1}<50 \%, \mathrm{mMRC}>2$, and in the exacerbator patient. 
ExH was the best predictor of 5 years cumulative future risk of exacerbations. Besides $\mathrm{FEV}_{1}, \mathrm{mMRC}$, and ExH, which usually classify severity and risk in COPD patients, we think that IC/TLC ratio can be a complementary parameter to predict severe outcomes in COPD.

\section{Disclosure}

The authors report no conflicts of interest in this work.

\section{References}

1. Mathers CD, Loncar D. Projections of global mortality and burden of disease from 2002 to 2030. PLoS Med. 2006;3(11):e442.

2. GBD 2015 Mortality and Causes of Death Collaborators. Global, regional, and national life expectancy, all-cause mortality, and causespecific mortality for 249 causes of death, 1980-2015: a systematic analysis for the Global Burden of Disease Study 2015. Lancet. 2016; 388(10053): 1459-1544.

3. GBD 2015 Mortality and Causes of Death Collaborators. Global, regional, and national incidence, prevalence, and years lived with disability for 310 diseases and injuries, 1990-2015: a systematic analysis for the Global Burden of Disease Study 2015. Lancet. 2016;388(10053): $1545-1602$.

4. GBD 2015 Mortality and Causes of Death Collaborators. Global, regional, and national deaths, prevalence, disability-adjusted life years, and years lived with disability for chronic obstructive pulmonary disease and asthma, 1990-2015: a systematic analysis for the Global Burden of Disease Study 2015. Lancet Respir Med. 2017;5(9):691-706.

5. Vogelmeier CF, Criner GJ, Martinez FJ, et al. Global strategy for the diagnosis, management, and prevention of chronic obstructive lung disease 2017 report. GOLD executive summary. Am J Respir Crit Care Med. 2017;195(5):557-582.

6. Lozano R, Naghavi M, Foreman K, et al. Global and regional mortality from 235 causes of death for 20 age groups in 1990 and 2010: a systematic analysis for the Global Burden of Disease Study 2010. Lancet. 2012;380(9859):2095-2128.

7. Donaldson GC, Seemungal TA, Bhowmik A, Wedzicha JA. Relationship between exacerbation frequency and lung function decline in chronic obstructive pulmonary disease. Thorax. 2002;57(10):847-852.

8. Wedzicha JA, Seemungal TA. COPD exacerbations: defining their cause and prevention. Lancet. 2007;370(9589):786-796.

9. Seemungal TA, Donaldson GC, Paul EA, Bestall JC, Jeffries DJ, Wedzicha JA. Effect of exacerbation on quality of life in patients with chronic obstructive pulmonary disease. Am J Respir Crit Care Med. 1998;157(5 Pt 1):1418-1422.

10. Seemungal TA, Hurst JR, Wedzicha JA. Exacerbation rate, health status and mortality in COPD - a review of potential interventions. Int J Chron Obstruct Pulmon Dis. 2009;4:203-223.

11. Flattet Y, Garin N, Serratrice J, Perrier A, Stirnemann J, Carballo S. Determining prognosis in acute exacerbation of COPD. Int J Chron Obstruct Pulmon Dis. 2017;12:467-475.

12. Roche N, Zureik M, Soussan D, Neukirch F, Perrotin D; Urgence BPCO (COPD Emergency) Scientific Committee. Predictors of outcomes in COPD exacerbation cases presenting to the emergency department. Eur Respir J. 2008;32(4):953-961.

13. Anzueto A. Impact of exacerbations on COPD. Eur Respir Rev. 2010; 19(116):113-118.

14. Groenewegen KH, Schols AM, Wouters EF. Mortality and mortalityrelated factors after hospitalization for acute exacerbation of COPD. Chest. 2003;124(2):459-467.

15. Soler-Cataluna JJ, Martinez-Garcia MA, Roman Sanchez P, Salcedo E, Navarro M, Ochando R. Severe acute exacerbations and mortality in patients with chronic obstructive pulmonary disease. Thorax. 2005; 60(11):925-931.
16. Celli BR, Decramer M, Wedzicha JA, et al. An official American Thoracic Society/European Respiratory Society statement: research questions in COPD. Eur Respir J. 2015;45(4):879-905.

17. Celli BR. Predictors of mortality in COPD. Respir Med. 2010;104(6): 773-779.

18. Celli BR, Cote CG, Marin JM, et al. The body-mass index, airflow obstruction, dyspnea, and exercise capacity index in chronic obstructive pulmonary disease. $N$ Engl J Med. 2004;350(10):1005-1012.

19. Cote CG, Pinto-Plata V, Kasprzyk K, Dordelly LJ, Celli BR. The 6-min walk distance, peak oxygen uptake, and mortality in COPD. Chest. 2007;132(6): 1778-1785.

20. Hurst JR, Vestbo J, Anzueto A, et al. Susceptibility to exacerbation in chronic obstructive pulmonary disease. $N$ Engl J Med. 2010;363(12): $1128-1138$.

21. Lange P, Marott JL, Vestbo J, et al. Prediction of the clinical course of chronic obstructive pulmonary disease, using the new GOLD classification: a study of the general population. Am J Respir Crit Care Med. 2012;186(10):975-981.

22. Martinez FJ, Foster G, Curtis JL, et al. Predictors of mortality in patients with emphysema and severe airflow obstruction. Am J Respir Crit Care Med. 2006;173(12):1326-1334.

23. Nishimura K, Izumi T, Tsukino M, Oga T. Dyspnea is a better predictor of 5-year survival than airway obstruction in patients with COPD. Chest. 2002;121(5):1434-1440.

24. de-Torres JP, Marin JM, Pinto-Plata V, et al. Is COPD a progressive disease? A long term bode cohort observation. PLoS One. 2016;11(4): e0151856.

25. Casanova $\mathrm{C}$, Cote $\mathrm{C}$, de Torres JP, et al. Inspiratory-to-total lung capacity ratio predicts mortality in patients with chronic obstructive pulmonary disease. Am J Respir Crit Care Med. 2005;171(6):591-597.

26. O'Donnell DE, Webb KA, Neder JA. Lung hyperinflation in COPD: applying physiology to clinical practice. COPD Res Pract. 2015; 1(1):4.

27. Ramon MA, Ferrer J, Gimeno-Santos E, et al. Inspiratory capacityto-total lung capacity ratio and dyspnoea predict exercise capacity decline in COPD. Respirology. 2016;21(3):476-482.

28. Albuquerque AL, Nery LE, Villaca DS, et al. Inspiratory fraction and exercise impairment in COPD patients GOLD stages II-III. Eur Respir J. 2006;28(5):939-944.

29. Cebollero P, Zambom-Ferraresi F, Hernandez M, Hueto J, Cascante J, Anton MM. Inspiratory fraction as a marker of skeletal muscle dysfunction in patients with COPD. Rev Port Pneumol (2006). 2017;23(1):3-9.

30. Wedzicha JA. Mechanisms of chronic obstructive pulmonary disease exacerbations. Ann Am Thorac Soc. 2015;12(Suppl 2):S157-S159.

31. Zaman M, Mahmood S, Altayeh A. Low inspiratory capacity to total lung capacity ratio is a risk factor for chronic obstructive pulmonary disease exacerbation. Am J Med Sci. 2010;339(5):411-414.

32. French A, Balfe D, Mirocha JM, Falk JA, Mosenifar Z. The inspiratory capacity/total lung capacity ratio as a predictor of survival in an emphysematous phenotype of chronic obstructive pulmonary disease. Int J Chron Obstruct Pulmon Dis. 2015;10:1305-1312.

33. Tantucci C, Donati $\mathrm{P}$, Nicosia F, et al. Inspiratory capacity predicts mortality in patients with chronic obstructive pulmonary disease. Respir Med. 2008;102(4):613-619.

34. Miller MR, Hankinson J, Brusasco V, et al. Standardisation of spirometry. Eur Respir J. 2005;26(2):319-338.

35. Wanger J, Clausen JL, Coates A, et al. Standardisation of the measurement of lung volumes. Eur Respir J. 2005;26(3):511-522.

36. Quanjer PH, Tammeling GJ, Cotes JE, Pedersen OF, Peslin R, Yernault JC. Lung volumes and forced ventilatory flows. Report Working Party Standardization of Lung Function Tests, European Community for Steel and Coal. Official Statement of the European Respiratory Society. Eur Respir J Suppl. 1993;6(Suppl 16):5-40.

37. Vestbo J, Hurd SS, Agusti AG, et al. Global strategy for the diagnosis, management, and prevention of chronic obstructive pulmonary disease: GOLD executive summary. Am J Respir Crit Care Med. 2013; 187(4):347-365. 
38. Celli BR, Decramer M, Liu D, Metzdorf N, Asijee GM, Tashkin DP. Defining a COPD composite safety endpoint for demonstrating efficacy in clinical trials: results from the randomized, placebo-controlled UPLIFT(R) trial. Respir Res. 2016;17(1):48.
39. Miravitlles M, Soler-Cataluna JJ, Calle M, et al. Spanish guidelines for management of chronic obstructive pulmonary disease (GesEPOC) 2017. Pharmacological treatment of stable phase. Arch Bronconeumol. 2017;53(6):324-335.

International Journal of COPD

\section{Publish your work in this journal}

The International Journal of COPD is an international, peer-reviewed journal of therapeutics and pharmacology focusing on concise rapid reporting of clinical studies and reviews in COPD. Special focus is given to the pathophysiological processes underlying the disease, intervention programs, patient focused education, and self management protocols.
Dovepress

This journal is indexed on PubMed Central, MedLine and CAS. The manuscript management system is completely online and includes a very quick and fair peer-review system, which is all easy to use. Visit $\mathrm{http}: / / \mathrm{www}$.dovepress.com/testimonials.php to read real quotes from published authors.

Submit your manuscript here: http://www.dovepress.com/international-journal-of-chronic-obstructive-pulmonary-disease-journal 